\title{
Association of angiotensin-converting enzyme inhibitors (ACEls) and angiotensin-receptor blockers (ARBs) with risk of mortality, severity or SARS-CoV-2 test positivity in COVID-19 patients: A systematic review and meta- analysis
}

Mohitosh Biswas ( $\square$ biswas_07pharm@ru.ac.bd)

University of Rajshahi

Most. Sumaiya Khatun Kali

University of Rajshahi

\section{Systematic Review}

Keywords: SARS-CoV-2, COVID-19, angiotensin-converting enzyme inhibitors, angiotensin-receptor blockers, clinical outcomes

Posted Date: July 7th, 2020

DOI: https://doi.org/10.21203/rs.3.rs-39141/v1

License: (c) (i) This work is licensed under a Creative Commons Attribution 4.0 International License. Read Full License 


\section{Abstract}

Effects of angiotensin-converting enzyme inhibitors (ACEIs) and angiotensin II receptor blockers (ARBs) in the treatment of COVID-19 is highly debated. It was aimed to assess aggregated risk by investigating the association of ACEIs/ARBs users against non-users of ACEIs/ARBs with the risk of mortality or severe clinical manifestations or magnitude of SARS-CoV-2 test positivity in COVID-19 patients. Systematic literature search was carried out in different databases for eligible studies. The pooled relative risks (RRs) were measured using RevMan software where $P<0.05$ was set as statistical significance. In total, 10 studies were included in this analysis. After pooled estimation, it was demonstrated that SARS-CoV-2 positive patients taking ACEIs/ARBs were not associated with increased risk of mortality as compared to those not taking ACEIs/ARBs (RR 0.89; 95\% $\mathrm{Cl} 0.64-1.23 ; P=0.48$ ). Further, the risk of composite severe clinical manifestations was not found significantly different between the positive patients with or without ACEls/ARBs users (RR 1.29; 95\% Cl 0.81-2.04; $P=0.28$ ). There was no risk difference for SARS-CoV-2 test positivity in patients with or without ACEls/ARBs users (RR 1.00; 95\% Cl 0.95-1.05; $P=0.91$ ). These findings may augment current professional society guidelines for not discontinuing ACEls/ARBs in treating COVID-19 patients where it is clinically indicated.

\section{Introduction}

Coronavirus disease 2019 (COVID-19) caused by the severe acute respiratory syndrome coronavirus 2 (SARS-CoV2) is leading to huge morbidity and mortality throughout the world since it was first detected in early December of 2019 in Wuhan, China ${ }^{1}$. It has already been established that the SARS-CoV-2 binds to the angiotensin-converting enzyme 2 (ACE2) receptor of extracellular domain of the transmembrane to gain entry into the host cells ${ }^{1,2}$. Angiotensin-converting enzyme inhibitors (ACEI) and angiotensin II receptor blockers (ARBs) are frontline therapies in treating cardiovascular disorders including hypertension and diabetes, however, they may upregulate ACE2 expression in some animal models ${ }^{1,3,4}$. But data are limited for human studies showing variations on plasma ACE2 levels, most importantly no study had identified on their effect on lung-specific expression of ACE2 ${ }^{1,5}$.

It is alarming that COVID-19 patients with comorbidities especially with hypertension, diabetes, and cardiovascular diseases have been found to be associated with the highest adverse clinical outcomes e.g. deaths ${ }^{6,7}$. This may lead to clinical concerns that patients who are taking ACEIs/ARBs for combating cardiovascular diseases along with hypertension and diabetes are at an increased risk for becoming infected with SARS-CoV- 2 and were being at the highest risk of worst clinical outcomes ${ }^{1,8}$. However, in this clinical debating situations, it has also been postulated that the ACE2 upregulation may improve clinical outcomes in SARS-CoV- 2 infected patients by protecting lung injury ${ }^{9}$. Furthermore, in certain high-risk SARS-CoV-2 infected patients, the removal of ACEls or ARBs may be detrimental ${ }^{5}$. In spite of lacking sufficient robust evidence, several professional societies have recommended to continue the administration of these medications in patients with COVID19 1 .

It is therefore expected that researcher may have explored the associations of taking ACEIs/ ARBs with increased risk of mortality or severe clinical manifestations (e.g. admitted to intensive care unit (ICU)/using mechanical ventilation/deaths) or even the magnitude of positivity with SARS-CoV-2 infection test during COVID-19 pandemic.

To date, only one meta-analysis appeared in the literature but has several methodological limitations ${ }^{10}$. First of all, it didn't clearly group patients with or without ACEls/ARBs users for estimating its effects on the SARS-CoV-2 
infection. Secondly, when estimating aggregated risk of clinical outcomes e.g. mortality or severity, this metaanalysis used data from some studies which is not either found in the literature nor the mother studies itself didn't have clear data on the patients using ACEls/ARBs versus no-users of ACEls/ARBs but adjusted with covariates, which makes come controversy regarding the outcomes of this meta-analysis.

Another systematic review conducted by Mackey $\mathrm{K}$ et al. 2020 reported the association of ACEls/ARBs users versus non-ACEIs/ARBs users with SARS-CoV-2 test positivity in limited perspectives ${ }^{11}$. However, severity of COVID-19 illness was not reported for the patients with or without ACEls/ARBs users but was adjusted with other covariates in this analysis, which certainly renders lacking robust evidence regarding these conflicts. Most importantly, this analysis used majority of the data from preprint articles which is not peer-reviewed making this analysis some concerns $^{11}$.

It is evident from the perspectives of current controversy that a robust study is needed showing the association of clinical manifestations of COVID-19 with or without ACEIs/ARBs users. Meanwhile, new studies may appear in the literature which needs to be incorporated to update the literature. This study was therefore aimed to assess aggregated risk of mortality or severity of illness or SARS-CoV-2 test positivity in COVID-19 patients with or without ACEls/ARBs users.

\section{Methods}

\section{Literature search}

Literatures were searched in PubMed from the inception to May 31, 2020 following the Preferred Reporting Items for Systematic Reviews and Meta-Analyses (PRISMA) guidelines as described elsewhere ${ }^{12}$. Keywords were searched as "2019 novel coronavirus with ACEIs/ARBs" or "2019-nCoV with ACEIs/ARBs" or "SARS-CoV-2 with ACEIs/ARBs" or "COVID-19 with ACEIs/ARBs" or "angiotensin-converting enzyme inhibitors (ACEIs) with COVID-19/SARS-CoV-2" or "angiotensin II receptor blockers (ARBs) with COVID-19/SARS-CoV-2" or "SARS-CoV-2 with ACEIs/ARBs" AND "clinical outcomes or death or severe illness or severe clinical outcomes or test positivity with SARS-CoV-2 or clinical features/characteristics". Additionally, different important journal websites e.g. New England Journal of Medicine, Lancet, JAMA and Nature were checked for the relevant articles.

\section{Inclusion criteria}

The studies were included if fulfilling the following criteria; (i) Studies must have two arms of COVID-19 patients in which one arm used ACEIs/ARBs whereas the other arm didn't use ACEls/ARBs (ii) Studies must have reported outcomes for at least one of the three clinical outcomes in both arms (a) mortality, (b) composite severe clinical manifestations which include combination of patients admitted to ICU/using mechanical ventilation/mortality (c) magnitude of SARS-CoV-2 test positivity (iii) Studies must be original peer-reviewed published research that had sufficient data to be included as described above.

\section{Exclusion criteria}

The studies were excluded based on the following criteria (i) if the study had only one arm of treatment group using either ACEls or ARBs but didn't have other arm (ii) if the study didn't clearly report outcomes data for selected two 
arms of patients as described above (iii) the studies were also excluded if it was reviews, systematic reviews, viewpoint, perspective or correspondence.

\section{Data extraction, validity and quality assessment}

Rayyan QCRI, a systematic review software tool ${ }^{13}$ was used for primary selection of the studies after importing all the literature search histories in this software following inclusion and exclusion criteria. For final selection of the studies, full texts of all primary included studies were retrieved and was checked one by one. When the articles were finally selected, full text of included studies were carefully checked for data synthesis and quality assessment purposes. All the selection process was carried out by two investigators anonymously and at the end of selection, any disagreement was resolved by principle investigator. Data synthesis and entry was double checked and validated by a third independent reviewer. For determining the quality of included studies, Newcastle Ottawa assessment scale guidelines were followed as described elsewhere ${ }^{14}$.

\section{Statistical analysis}

Estimation of pooled effects were calculated as risk ratios (RRs) and 95\% confidence interval (Cl) using the MantelHaenssel $(\mathrm{M}-\mathrm{H})$ method following either random or fixed effect model based on the levels of heterogeneity of the included studies. Heterogeneity in the forest plot was evaluated by using the Cochrane chi-square-based Q-test and regarded as significant if $\mathrm{p}$ value was less than $0.1^{15}$. Meanwhile, the statistic of $\mathrm{I}^{2}$ was used to efficiently test for the heterogeneity, where $\mathrm{I}^{2}<25 \%, \mathrm{I} 2=25-50 \%$ and $\mathrm{I} 2>50 \%$ indicates low, moderate and high degree of heterogeneity, respectively ${ }^{16}$. Random effect model was used to estimate pooled effects if $\mathrm{I}^{2}>50$ and fixed effects model was applied to calculate pooled effects when $\mathrm{I}^{2}<50$. Sensitivity analyses were carried out to measure any significant risk differences in-between the studies especially if heterogeneity was found. This was accomplished by removing the included study one after another. In addition, publication bias was carried out by the visual inspection of funnel plot where symmetrical distribution of plot indicated the absence of publication bias ${ }^{17}$. Funnel plot asymmetry was also assessed with the Egger's test ${ }^{18}$. Review-Manager software (RevMan version 5.3 Windows; The Cochrane Collaboration, Oxford, UK) was used for analyzing all data where the level of statistical significance was set as $<0.05$ (2-sided).

\section{Results}

\section{General characteristics and quality of included studies}

Selection process of included studies as undertaken following PRISMA guidelines for this meta-analysis is shown in Figure 1. In total, 10 studies comprising of 49,188 patients were included in this analysis. Of these, 4,274 SARSCoV-2 positive patients were taking ACEls/ARBs whereas 8,714 positive patients were non users of ACEIs/ARBs ${ }^{1,19-27}$. Of these, eight studies provided data on mortality outcome, seven studies provided data on composite severe clinical manifestations outcome and only two studies provided data on SARS-CoV-2 test positivity as shown in Table 1. Clinical outcomes were reported for majority of the COVID-19 patients with hypertension 19,20,22-24,26,27 although only three studies ${ }^{1,21,25}$ reported outcomes with multi-comorbidities including hypertension and one study separately reported outcome for hypertensive COVID-19 patients as well as patients with other comorbidities ${ }^{23}$. The important baseline characteristics of the included studies are summarized in Table 
1. The quality of included studies as determined by the Newcastle-Ottawa assessment scale was of high quality (score ranges between 7-9), as shown in Supplementary Table 1.

\section{Association of ACEls/ARBs users vs non-users of ACEIs/ARBs with the risk of mortality in patients with COVID-19}

The association of mortality was assessed in COVID-19 patients where 2,332 patients were taking ACEls/ARBs and 6,743 patients were non-users of ACEIs/ARBs. As shown in Figure 2, the results of this meta-analysis after pooled estimation indicated that SARS-CoV-2 positive patients taking ACEls/ARBs were not associated with increased risk of mortality as compared to those positive patients not taking ACEls/ARBs (RR $0.89 ; 95 \% \mathrm{Cl} 0.64-1.23 ; P=0.48$ ). This finding may be considered as novel since no study has measured the pooled effects of mortality for ACEls/ARBs users against non-users of ACEls/ARBs in COVID-19 patients using such a large sample size. Whilst controversy whether it should or should not continue ACEIs/ARBs in these patients, this aggregated finding may be considered as highest evidence and may able to reduce debating in this regard.

\section{Association of ACEIs/ARBs users vs non-users of ACEls/ARBs with the risk of composite severe clinical manifestations in patients with COVID-19}

The risk of composite severe clinical manifestations (admitted to ICU/using mechanical ventilation/mortality) was not found significantly different between the SARS-CoV-2 positive patients using ACEls/ARBs versus non-users of ACEIs/ARBs (RR 1.29; 95\% Cl 0.81-2.04; $\mathrm{P}=0.28$ ), as shown in Figure $3 \mathrm{~A}$.

\section{Association of ACEIs/ARBs users vs non-users of ACEls/ARBs with the risk of SARS-COV-2 test positivity in patients with COVID-19}

Many COVID-19 patients had multiple comorbidities and were using ACEls/ARBs before SARS-CoV-2 testing, even many were started to use these medications after hospital admission. On the other hand, many patients were not using ACEIs/ARBs before or during hospitalization. It was utmost importance to investigate whether prior or during hospitalization use of ACEIs/ABRs increased the magnitude of infections compared to those patients never using these medications. After pooled estimation, it was found that the magnitude of SARS-CoV-2 test positivity had no risk difference between the COVID-19 patients with or without prior or during hospitalization use of ACEIs/ARBs (RR 1.00; 95\% Cl 0.95-1.05; P = 0.91), as shown in Figure 3B. This finding may also be considered as novel insights since using ACEIs/ARBs was not associated with increased risk of SARS-CoV-2 test positivity in COVID-19 patients, although it was statistically insignificant.

\section{Heterogeneity, sensitivity analysis and publication bias}

There was significant heterogeneity in studies that tested mortality and severe clinical manifestations for ACEls/ARBs users against non-users of ACEls/ARBs. Ethnicity, age, sex and comorbidities may be accountable for 
high level of heterogeneity since these variables were not adjusted for clinical outcomes in majority of included studies. However, heterogeneity was completely disappeared in studies that assessed SARS-CoV-2 test positivity for ACEls/ARBs users against non-users of ACEIs/ARBs. In sensitivity analysis, no single study was found to excessively affecting the pooled effects or heterogeneity.

In sensitivity analysis, it was also found that there was no risk difference for severe clinical manifestations in COVID-19 hypertensive patients with or without ACEIs/ARBs users although it was statistically insignificant (RR 1.00; 95\% Cl 0.75-1.33; $P=0.99$ ), figure not shown here. Although number of studies included for assessing publication bias in this analysis were very small $(n=8)$, even after it was found from the visual inspection of the funnel plot that there was no publication bias, as shown in Figure 4.

In summary, using ACEIs/ARBs in SARS-CoV-2 positive patients neither increasing the risk of viral infectivity nor severe clinical manifestations significantly compared to those patients not using these medications. Instead, using ACEIs/ARBs in these patients was associated with a trend towards reduction of the risk of mortality as compared to those not using these medications.

\section{Discussion}

After estimating aggregated risk, this analysis providing evidence that neither severe clinical manifestations nor magnitude of SARS-CoV-2 infectivity were significantly different with or without ACEls/ARBs users in patients with COVID-19. Interestingly, mortality was slightly reduced (11\%) in ACEIs/ARBs users of SARS-CoV-2 positive patients compared to those not using these medications although it was statistically insignificant. These findings are consistent in line with other analyses carried out by independent researchers ${ }^{10,11}$. Most importantly, the findings of current analysis support different professional societies recommendations for continuing ACEls/ARBs irrespective whether it is contraindicated for other clinical conditions not just COVID-19 reason ${ }^{1}$.

Without elucidating exact molecular mechanism, it would not be plausible to accurately explain governing the trends towards slightly reduction of mortality for using ACEIS/ARBs in patients with COVID-19 compared to those not with these medications. However, with accumulating existing evidence and data, it is reasonably believed that upregulation of ACE2 may acting as biological sword and is organ protective e.g. protecting lung injury, myocardium and kidney which is mainly executed by using ACEls/ARBs in these patients ${ }^{5}$. From the findings of current study, it may be postulated that organo-protective nature of upregulated ACE2 directly induced by the ACEls/ARBs in COVID-19 patients was probably associated with the reduction of deaths as compared to those not with ACEIs/ARBs. This is because, it has already found that COVID-19 patients appeared to have elevated levels of plasma angiotensin II, which in turn causing lung injury ${ }^{5,28}$. It was also found that COVID-19 was particularly severe in patients with cardiovascular diseases and many of these patients had active myocardial injury, myocardial stress and cardiomyopathy provoking the severity of illness and even deaths ${ }^{5,29-34}$. This may be due the downregulation of ACE2 for SARS-CoV-2 infection and replication which in turn may be unable to exert protective effects in organs ${ }^{5,9}$. Since no study has proven experimentally the association between ACEls/ARBs uses and reduction of mortality in COVID-19 patients found in this study, therefore future experimental studies are warranted to firmly establish the exact molecular mechanism behind this scientifically novel outcome.

Although using ACEIs/ARBs in COVID-19 patients in general slightly increasing the risk of composite severe clinical manifestations (admitted to ICU/using mechanical ventilation/mortality) but failed to reach statistically significant. Importantly, when the association was assessed only for hypertensive COVID-19 patients, the risk was drastically 
fall and there was almost no risk difference with or without ACEls/ARBs users. This indicated that using ACEIs/ARBs in hypertensive COVID-19 patients had actually no significant risk differences compared to those not

using these medications. A recent study ${ }^{35}$ conducted by Mancia et al. 2020 after multivariable adjustment indicated that neither ACEIs or ARBs had a significant association with the risk of COVID-19, which is consistent with the findings of the present study.

Magnitude of infection positivity caused by SARS-CoV-2 was not found any significantly difference with or without ACEIs/ARBs users which is scientifically exciting and may be considered new insights for COVID-19 patients. Again, future experimental studies are warranted to elucidate molecular mechanism for these associations.

This is an important concern whether it should or should not continue ACEls/ABRs in COVID-19 patients especially with hypertension because these medications are the most prevalent antihypertensive medications among all therapeutic classes used generally ${ }^{24}$. Because the results of this meta-analysis pooled data from individual studies that were unadjusted for known confounders e.g. age, sex, race, ethnicity and comorbidities such as diabetes, chronic kidney disease and heart failure, therefore, the findings of the current study can't completely address the complexity of this question. Future clinical studies are warranted again to address these issues. However, with aggregating existing data appeared in the literature to date, this study providing evidence that using ACEls/ARBs in COVID-19 patients in general and in particular hypertensive patients were not associated with increased risk for neither composite severe clinical manifestations nor SARS-CoV-2 test positivity compared to those patients not taking these medications. Instead, using ACEIs/ARBs in these patients compared to non-using were associated with statistically insignificant slightly reduction of the risk of mortality. These evidences may be considered as novel insights in the current perspectives of controversy and lack of sufficient robust evidences in the literature.

\section{Limitations}

Although this study has great novelty in terms of providing evidence whether ACEls/ARBs should or should not continue with COVID-19 patients, however, there are some limitations of this analysis. Firstly, it was not possible to extract data to examine the effects of age, sex, and comorbidities in ACEls/ABRs users against non-users of ACEIs/ARBs which may be accountable for high level of heterogeneity. Secondly, due to unavailability of data, it was not possible to estimate the dosage regimen effects of ACEls/ARBs. Thirdly, there was no information about the types of drugs used in users vs. non-users of ACEIs/ARBs in majority of the included studies since there are lots of drugs fall into the classes of ACEls/ARBs which may increase inconsistency of the outcomes. It is therefore suggested to address these issues in future clinical studies.

\section{Conclusions}

The findings of this analysis indicated that using ACEIs/ARBs in SARS-CoV-2 positive patients were not associated with increased risk of mortality, rather it had a trend towards slightly reduction of the risk of mortality. Further, it was also found that neither severe clinical manifestations nor magnitude of SARS-CoV-2 infectivity were significantly different with or without ACEls/ARBs users. These findings may augment current professional society guidelines for not discontinuing ACEIs/ARBs in treating COVID-19 patients where it is clinically indicated.

\section{Declarations}

Conflict of interest: No conflict of interest. 
Funding: No funding was available for this research.

Data availability: All data used in this analysis is freely available upon request.

\section{Acknowledgements}

Authors are greatly acknowledging the contribution of an independent third reviewer named Mr. Shawonur Rahman (MSR) for his time and patience to double check and validate all data extraction and entry.

\section{References}

1.Mehta, N. et al. Association of Use of Angiotensin-Converting Enzyme Inhibitors and Angiotensin II Receptor Blockers With Testing Positive for Coronavirus Disease 2019 (COVID-19). JAMA Cardiol. (2020) doi:10.1001/jamacardio.2020.1855.

2.Sanders, J. M. et al. Pharmacologic Treatments for Coronavirus Disease 2019 (COVID-19): A Review. JAMA Journal of the American Medical Association (2020) doi:10.1001/jama.2020.6019.

3.Ishiyama, Y. et al. Upregulation of Angiotensin-Converting Enzyme 2 after Myocardial Infarction by Blockade of Angiotensin II Receptors. Hypertension 43, 970-976 (2004).

4.Ferrario, C. M. et al. Effect of angiotensin-converting enzyme inhibition and angiotensin II receptor blockers on cardiac angiotensin-converting enzyme 2. Circulation 111, 2605-2610 (2005).

5.Vaduganathan, M. et al. Renin-Angiotensin-Aldosterone System Inhibitors in Patients with Covid-19. N. Engl. J. Med. 382, 1653-1659 (2020).

6.Biswas, M. et al. Effects of Sex, Age and Comorbidities on the Risk of Infection and Death Associated with COVID-19: A Meta-Analysis of 47807 Confirmed Cases. SSRN Electron. J. (2020) doi:10.2139/ssrn.3566146.

7.Wu, Z. \& McGoogan, J. M. Characteristics of and Important Lessons from the Coronavirus Disease 2019 (COVID19) Outbreak in China: Summary of a Report of 72314 Cases from the Chinese Center for Disease Control and Prevention. JAMA - J. Am. Med. Assoc. (2020) doi:10.1001/jama.2020.2648.

8.Fang, L., Karakiulakis, G. \& Roth, M. Are patients with hypertension and diabetes mellitus at increased risk for COVID-19 infection? The Lancet Respiratory Medicine vol. 8 e21 (2020).

9.Gurwitz, D. Angiotensin receptor blockers as tentative SARS-CoV-2 therapeutics. Drug Development Research (2020) doi:10.1002/ddr.21656.

10.Xue Zhang, Jiong Yu, Li-Ya Pan, H.-Y. J. ACEI/ARB Use and Risk of Infection or Severity or Mortality of COVID19: A Systematic Review and Meta-Analysis. Pharmacol Res. 158, 104927 (2020).

11. Mackey, K. et al. Risks and Impact of Angiotensin-Converting Enzyme Inhibitors or Angiotensin-Receptor Blockers on SARS-CoV-2 Infection in Adults. Ann. Intern. Med. (2020) doi:10.7326/m20-1515.

12. Higgins J. P. T. et al. Cochrane Handbook for Systematic Reviews of Interventions version 6.0 (updated July 2019). Cochrane, 2019. Handbook (2019). 
13.Ouzzani, M., Hammady, H., Fedorowicz, Z. \& Elmagarmid, A. Rayyan-a web and mobile app for systematic reviews. Syst. Rev. 5, (2016).

14.Wells, G., Shea, B., O'Connell, D. \& Peterson, J. The Newcastle-Ottawa Scale (NOS) for assessing the quality of nonrandomised studies in meta-analyses. Ottawa, ON: Ottawa Hospital Research Institute http://www.ohri.ca/programs/clinical_epidemiology/oxford.asp (2000).

15.Lau, J., loannidis, J. P. A. \& Schmid, C. H. Quantitative synthesis in systematic reviews. Annals of Internal Medicine vol. 127 820-826 (1997).

16.Higgins, J. P. T., Thompson, S. G., Deeks, J. J. \& Altman, D. G. Measuring inconsistency in meta-analyses. British Medical Journal vol. 327 557-560 (2003).

17.Sutton, A. J., Duval, S. J., Tweedie, R. L., Abrams, K. R. \& Jones, D. R. Empirical assessment of effect of publication bias on meta-analyses. Br. Med. J. 320, 1574-1577 (2000).

18.Egger, M., Smith, G. D., Schneider, M. \& Minder, C. Bias in meta-analysis detected by a simple, graphical test. Br. Med. J. 315, 629-634 (1997).

19.Feng, Y. et al. COVID-19 with Different Severity: A Multi-center Study of Clinical Features. Am. J. Respir. Crit. Care Med. (2020) doi:10.1164/rccm.202002-04450C.

20.Li, J., Wang, X., Chen, J., Zhang, H. \& Deng, A. Association of Renin-Angiotensin System Inhibitors With Severity or Risk of Death in Patients With Hypertension Hospitalized for Coronavirus Disease 2019 (COVID-19) Infection in Wuhan, China. JAMA Cardiol. (2020) doi:10.1001/jamacardio.2020.1624.

21.Mehra, M. R., Desai, S. S., Kuy, S., Henry, T. D. \& Patel, A. N. Cardiovascular Disease, Drug Therapy, and Mortality in Covid-19. N. Engl. J. Med. (2020) doi:10.1056/nejmoa2007621.

22.Meng, J. et al. Renin-angiotensin system inhibitors improve the clinical outcomes of COVID-19 patients with hypertension. Emerging microbes \& infections vol. 9 757-760 (2020).

23. Reynolds, H. R. et al. Renin-Angiotensin-Aldosterone System Inhibitors and Risk of Covid-19. N Engl J Med. (2020) doi:10.1056/NEJMoa2008975.

24.Richardson, S. et al. Presenting Characteristics, Comorbidities, and Outcomes Among 5700 Patients Hospitalized With COVID-19 in the New York City Area. Jama (2020) doi:10.1001/jama.2020.6775.

25.Guo, T. et al. Cardiovascular Implications of Fatal Outcomes of Patients with Coronavirus Disease 2019 (COVID19). JAMA Cardiol. (2020) doi:10.1001/jamacardio.2020.1017.

26.Yang, G. et al. Effects Of ARBs And ACEls On Virus Infection, Inflammatory Status And Clinical Outcomes In COVID-19 Patients With Hypertension: A Single Center Retrospective Study. Hypertension HYPERTENSIONAHA.120.15143 (2020) doi:10.1161/HYPERTENSIONAHA.120.15143.

27.Zhang, P. et al. Association of Inpatient Use of Angiotensin Converting Enzyme Inhibitors and Angiotensin II Receptor Blockers with Mortality Among Patients With Hypertension Hospitalized With COVID-19. Circ. Res. (2020) doi:10.1161/circresaha.120.317134. 
28.Liu, Y. et al. Clinical and biochemical indexes from 2019-nCoV infected patients linked to viral loads and lung injury. Sci. China Life Sci. 63, 364-374 (2020).

29.Zhou, F. et al. Clinical course and risk factors for mortality of adult inpatients with COVID-19 in Wuhan, China: a retrospective cohort study. Lancet (2020) doi:10.1016/s0140-6736(20)30566-3.

30.Shi, S. et al. Association of Cardiac Injury with Mortality in Hospitalized Patients with COVID-19 in Wuhan, China. JAMA Cardiol. (2020) doi:10.1001/jamacardio.2020.0950.

31.Guan, W. et al. Clinical characteristics of 2019 novel coronavirus infection in China. N. Engl. J. Med. (2020) doi:10.1101/2020.02.06.20020974.

32.Ruan, Q., Yang, K., Wang, W., Jiang, L. \& Song, J. Clinical predictors of mortality due to COVID-19 based on an analysis of data of 150 patients from Wuhan, China. Intensive Care Medicine(2020) doi:10.1007/s00134-02005991-x.

33.Arentz, M. et al. Characteristics and Outcomes of 21 Critically III Patients with COVID-19 in Washington State. JAMA - Journal of the American Medical Association (2020) doi:10.1001/jama.2020.4326.

34.Wang, D. et al. Clinical Characteristics of 138 Hospitalized Patients with 2019 Novel Coronavirus-Infected Pneumonia in Wuhan, China. JAMA - J. Am. Med. Assoc. (2020) doi:10.1001/jama.2020.1585.

35.Mancia G, Rea F, Ludergnani M, Apolone G, C. G. Renin-Angiotensin-Aldosterone System Blockers and the Risk of Covid-19. N Engl J Med. (2020) doi:10.1056/NEJMoa2006923.

\section{Table}

Table 1. Baseline characteristics of included studies 


\begin{tabular}{|c|c|c|c|c|c|c|c|}
\hline $\begin{array}{l}\text { Author, } \\
\text { Year }\end{array}$ & Ethnicity & Study design & $\begin{array}{l}\text { Characteristics } \\
\text { of Patients } \\
\text { reporting } \\
\text { clinical } \\
\text { outcomes }\end{array}$ & $\begin{array}{l}\text { Median } \\
\text { age } \\
\text { (IQR); } \\
\% \text { of } \\
\text { male }\end{array}$ & $\begin{array}{l}\text { Sample } \\
\text { size }\end{array}$ & $\begin{array}{l}\text { Reported } \\
\text { clinical } \\
\text { outcomes }\end{array}$ & $\begin{array}{l}\text { Study } \\
\text { duration } \\
\text { with } \\
\text { follow- } \\
\text { up, days }\end{array}$ \\
\hline $\begin{array}{l}\text { Feng et al. } \\
2020\end{array}$ & China & $\begin{array}{l}\text { Retrospective, } \\
\text { multi-center } \\
\text { case-control } \\
\text { study }\end{array}$ & $\begin{array}{l}\text { COVID-19 with } \\
\text { hypertension }\end{array}$ & $\begin{array}{l}53 \\
(40-64) ; \\
56.9\end{array}$ & 476 & $\begin{array}{l}\text { severe clinical } \\
\text { manifestations }\end{array}$ & 44 \\
\hline $\begin{array}{l}\text { Li et al. } \\
2020\end{array}$ & China & $\begin{array}{l}\text { Retrospective, } \\
\text { single-center } \\
\text { case series }\end{array}$ & $\begin{array}{l}\text { COVID-19 with } \\
\text { hypertension }\end{array}$ & $\begin{array}{l}55.5 \\
(38-67) \\
52.2\end{array}$ & 1178 & $\begin{array}{l}\text { Mortality, } \\
\text { severe clinical } \\
\text { manifestations }\end{array}$ & 61 \\
\hline $\begin{array}{l}\text { Mehra et } \\
\text { al. } 2020\end{array}$ & $\begin{array}{l}\text { Asia, } \\
\text { Europe, } \\
\text { and } \\
\text { North } \\
\text { America }\end{array}$ & $\begin{array}{l}\text { Retrospective, } \\
\text { multi-center } \\
\text { case-control } \\
\text { study }\end{array}$ & $\begin{array}{l}\text { COVID-19 with } \\
\text { multi- } \\
\text { comorbidities }\end{array}$ & $\begin{array}{l}49 \pm 16 * \\
60\end{array}$ & 8910 & Mortality & 40 \\
\hline $\begin{array}{l}\text { Mehta et } \\
\text { al. } 2020\end{array}$ & USA & $\begin{array}{l}\text { Retrospective } \\
\text { cohort study }\end{array}$ & $\begin{array}{l}\text { COVID-19 with } \\
\text { multi- } \\
\text { comorbidities }\end{array}$ & $\begin{array}{l}48 \\
(21) * \\
40\end{array}$ & 18472 & $\begin{array}{l}\text { Mortality, } \\
\text { severe clinical } \\
\text { manifestations, } \\
\text { SARS-CoV-2 } \\
\text { test positivity }\end{array}$ & 36 \\
\hline $\begin{array}{l}\text { Meng et al. } \\
2020\end{array}$ & China & $\begin{array}{l}\text { Retrospective, } \\
\text { single-center } \\
\text { cohort study }\end{array}$ & $\begin{array}{l}\text { COVID-19 with } \\
\text { hypertension }\end{array}$ & $\begin{array}{l}64.5 \\
(55.8- \\
69) ; \\
57.1\end{array}$ & 417 & $\begin{array}{l}\text { Mortality, } \\
\text { severe clinical } \\
\text { manifestations }\end{array}$ & 44 \\
\hline $\begin{array}{l}\text { Reynolds } \\
\text { et al. } 2020\end{array}$ & USA & $\begin{array}{l}\text { Population- } \\
\text { based } \\
\text { observational } \\
\text { study }\end{array}$ & $\begin{array}{l}\text { COVID-19 with } \\
\text { hypertension } \\
\text { and other } \\
\text { comorbidities }\end{array}$ & $\begin{array}{l}64 \\
(54-75) ; \\
50.8\end{array}$ & 12594 & $\begin{array}{l}\text { Severe clinical } \\
\text { manifestations, } \\
\text { SARS-CoV-2 } \\
\text { test positivity }\end{array}$ & 46 \\
\hline $\begin{array}{l}\text { Richardson } \\
\text { et al. } 2020\end{array}$ & USA & $\begin{array}{l}\text { Prospective } \\
\text { case series }\end{array}$ & $\begin{array}{l}\text { COVID-19 with } \\
\text { hypertension }\end{array}$ & $\begin{array}{l}63 \\
(52-75) ; \\
60.3\end{array}$ & 5700 & $\begin{array}{l}\text { Mortality, } \\
\text { severe clinical } \\
\text { manifestations }\end{array}$ & 35 \\
\hline $\begin{array}{l}\text { Tao et al. } \\
2020\end{array}$ & China & $\begin{array}{l}\text { Retrospective } \\
\text { observational } \\
\text { study }\end{array}$ & $\begin{array}{l}\text { COVID-19 with } \\
\text { multi- } \\
\text { comorbidities }\end{array}$ & $\begin{array}{l}58.5 \\
(14.7) * \\
48.7\end{array}$ & 187 & Mortality & 32 \\
\hline $\begin{array}{l}\text { Yang et al } \\
2020\end{array}$ & China & $\begin{array}{l}\text { Retrospective, } \\
\text { single-center } \\
\text { cohort study }\end{array}$ & $\begin{array}{l}\text { COVID-19 with } \\
\text { hypertension }\end{array}$ & $\begin{array}{l}66 \\
(60-72) ; \\
48.8\end{array}$ & 126 & $\begin{array}{l}\text { Mortality, } \\
\text { severe clinical } \\
\text { manifestations }\end{array}$ & 49 \\
\hline
\end{tabular}




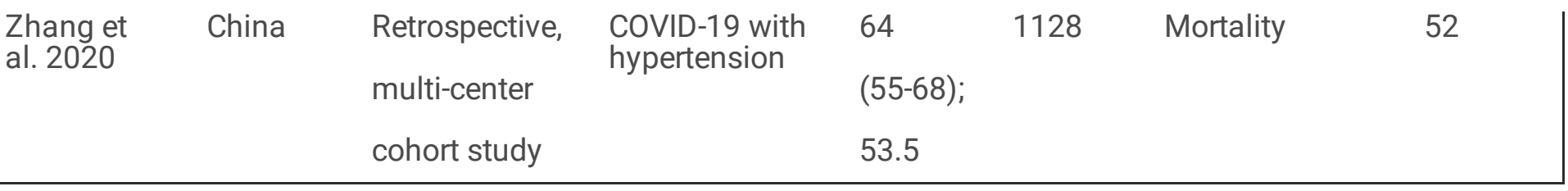

*age reported as mean with standard deviation (SD); IQR=Interquartile range; COVID-19= Corona virus disease-2019; SARS-CoV-2=Severe acute respiratory syndrome corona virus-2

\section{Figures}

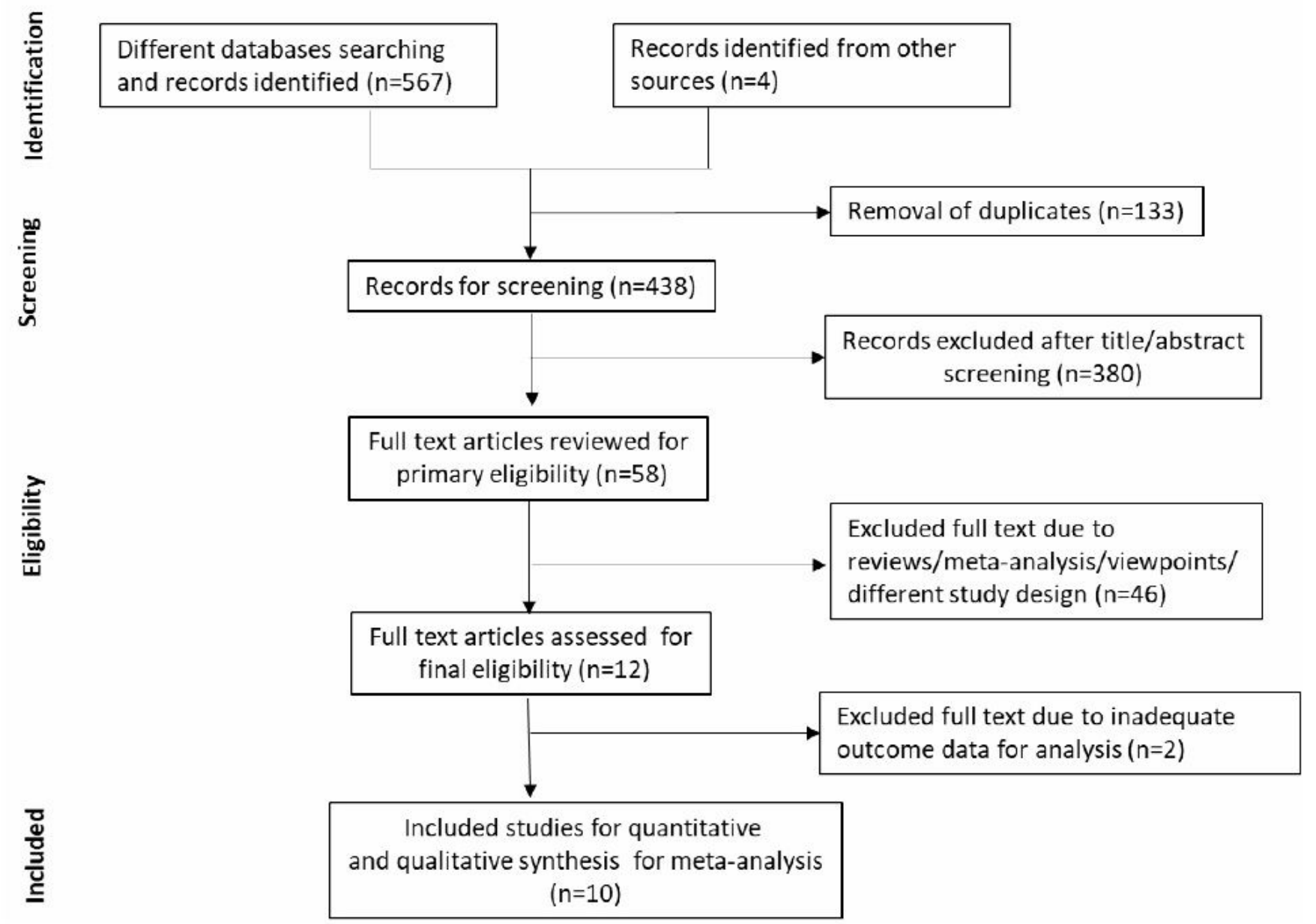

Figure 1

PRISMA flowchart showing the selection of studies for meta-analysis. 


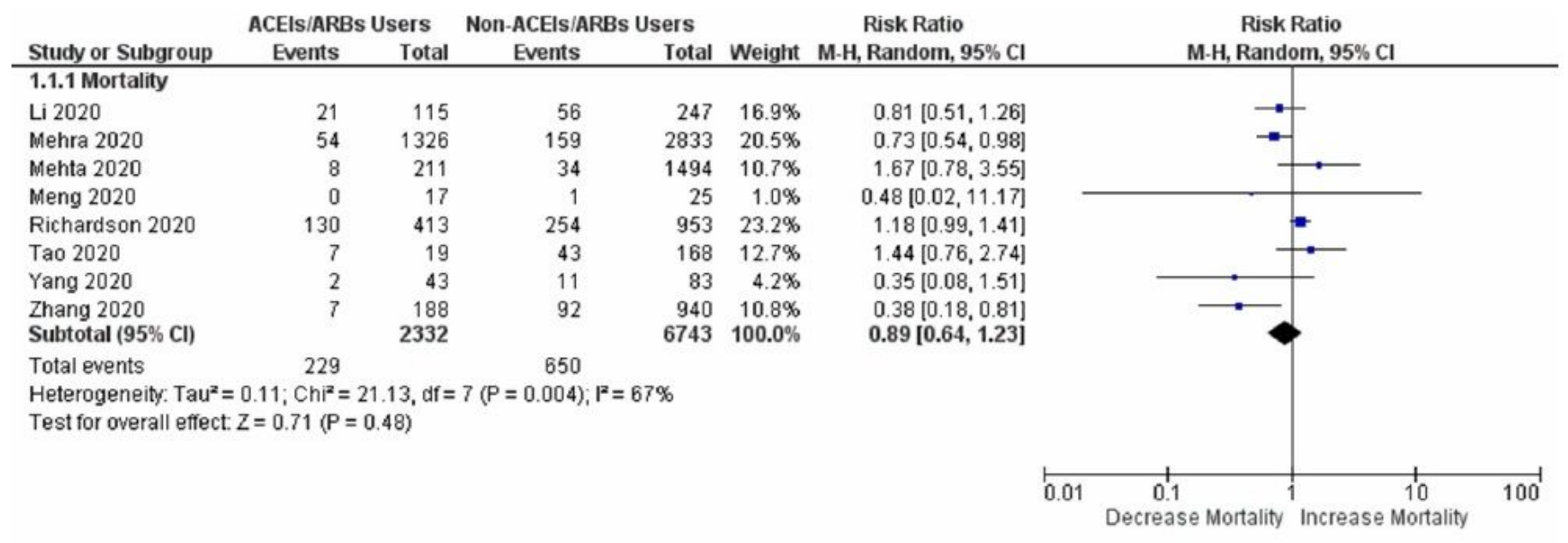

Figure 2

Forest plot of ACEIs/ARBs users against non-users of ACEIs/ARBs on the risk of mortality in patients with COVID-19.

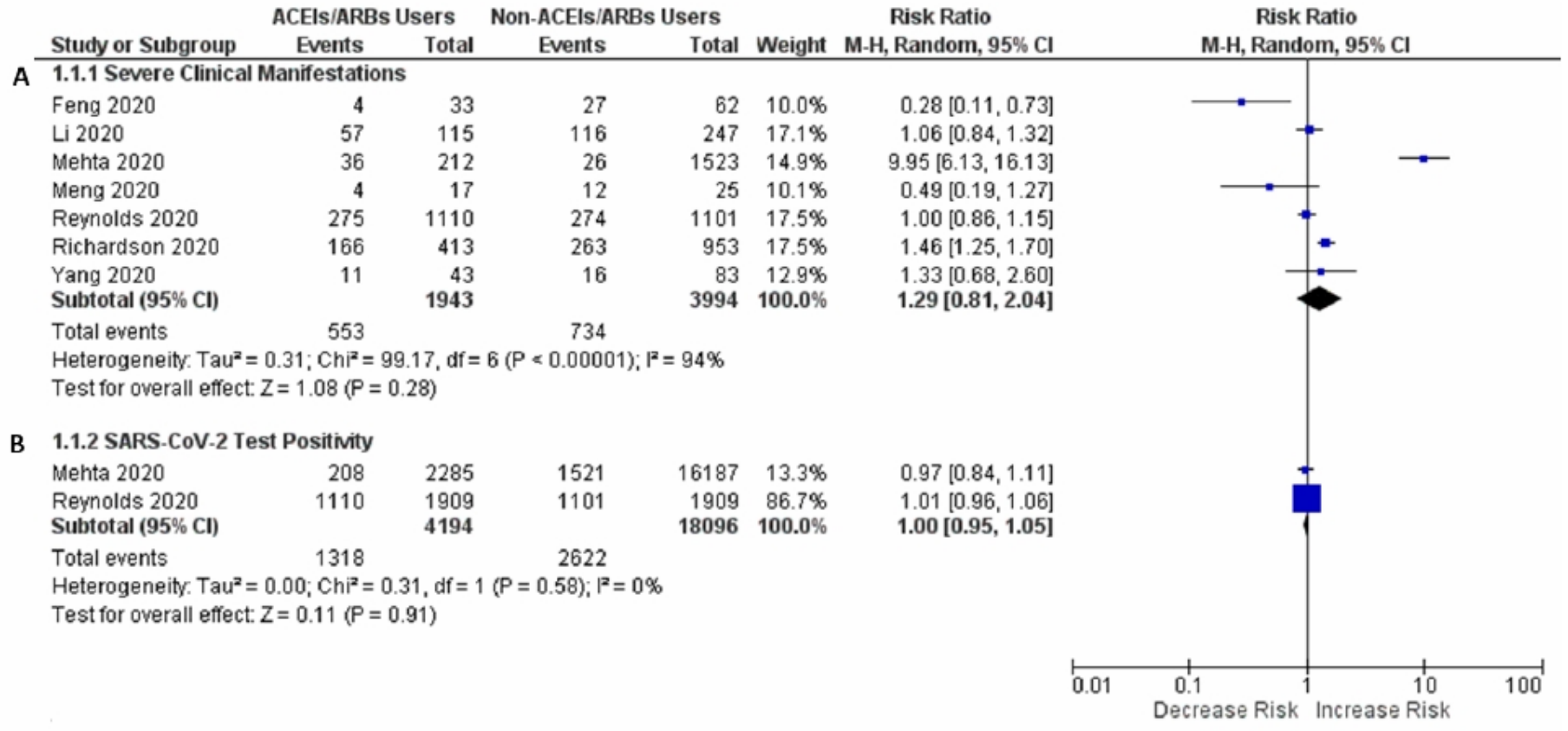

\section{Figure 3}

Forest plot of ACEls/ARBs users against non-users of ACEIs/ARBs on the risk of severe clinical manifestations (Fig. A) and SARS-CoV-2 test positivity (Fig. B) in patients with COVID-19. 


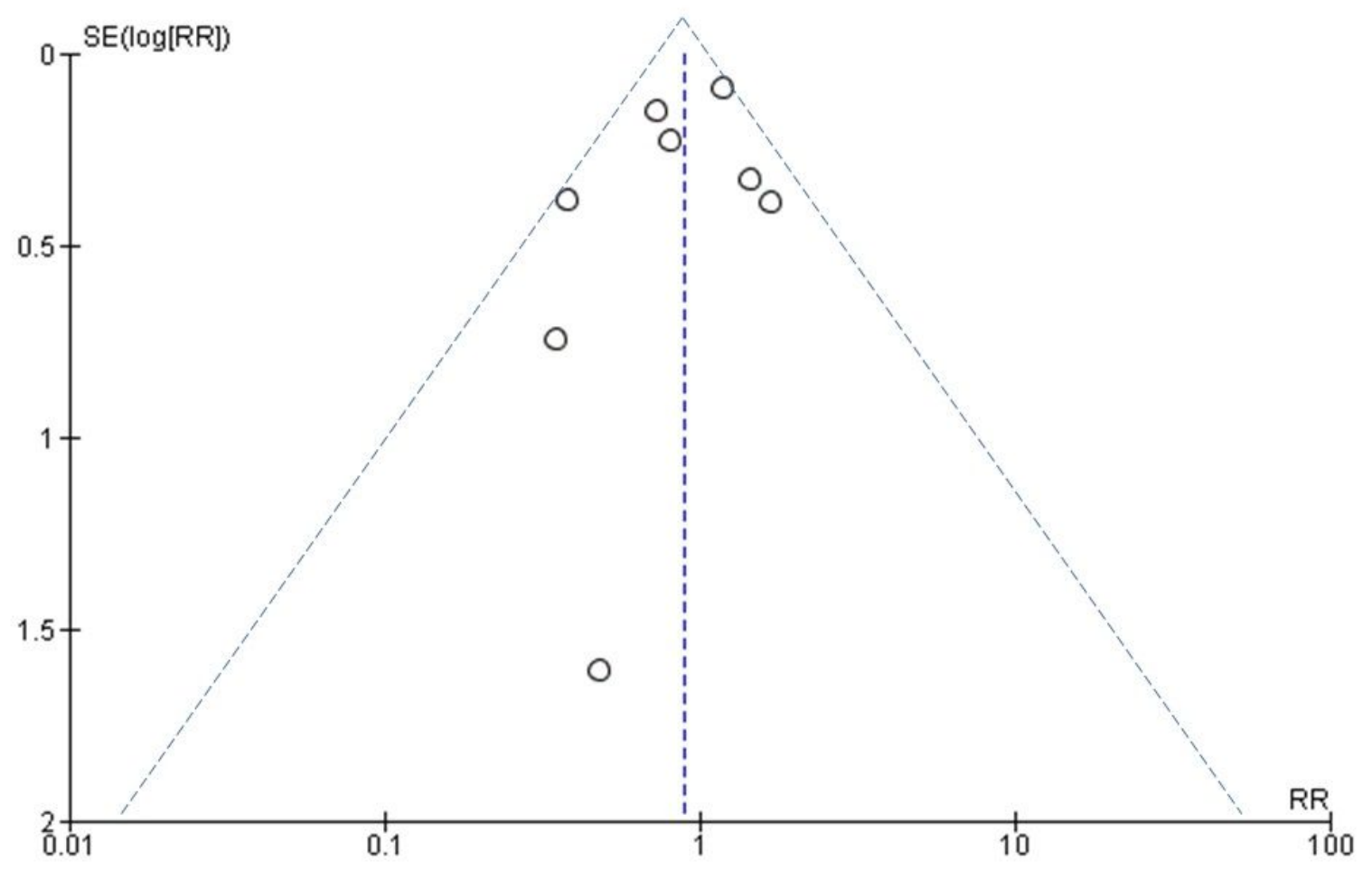

Figure 4

Funnel plot of ACEIs/ARBs users against non-users of ACEls/ARBs on the risk of mortality in patients with COVID19.

\section{Supplementary Files}

This is a list of supplementary files associated with this preprint. Click to download.

- SupplementaryTable1.docx 